\title{
Changes in the Degree of Patient Expectations for Patient- Centered Care in a Primary Care Setting
}

\author{
Chang-Jin Choi, Sun-Wook Hwang, Ha-Na Kim*
}

Department of Family Medicine, Seoul St. Mary's Hospital, The Catholic University of Korea College of Medicine, Seoul, Korea

\section{ABSTRACT}

Background: To date, the medical environment has been undergoing continual changes. It is therefore imperative that clinicians recognize the changing trends in the degree of patient expectations for patient-centered care. We conducted this study to examine changes in the degree of patient expectations for patient-centered care and the related socio-demographic factors in a primary care setting over a 5 -year period.

Methods: We evaluated patients' attitudes toward patient-centered care using the Patient-Practitioner Orientation Scale, which provides 'sharing' and 'caring' scores. The study included 359 and 468 patients in phase I (March-July, 2005) and II (March-July, 2010). We also examined the relationship of their changes to their socio-demographic factors.

Results: In phase II, as compared with phase I, the 'sharing' score was higher ( $3.67 \pm 0.68$ vs. $3.82 \pm$ $0.44 ; \mathrm{P}<0.001)$ and 'caring' one was lower $(4.01 \pm 0.57$ vs. $3.67 \pm 0.58 ; \mathrm{P}=0.001)$. Further, 'sharing' and 'caring' scores were associated with age, monthly income, education level, marital status, and the functional health status of patients.

Conclusion: These results would be of help for providing patient-centered care for patients because it makes clinicians are aware of the degree to which patients' expect it.

Keywords: Patients; Patient-Centered Care; Physician-Patient Relations; Primary Health Care

Received: July 21, 2014, Accepted: February 9, 2015

*Corresponding Author: Ha-Na Kim

Tel: +82-31-249-8246, Fax: +82-31-248-7404, E-mail: onef01@catholic.ac.kr

Korean Journal of Family Medicine

Copyright (C) 2015 The Korean Academy of Family Medicine

This is an open-access article distributed under the terms of the Creative Commons Attribution Non-Commercial License (http://creativecommons.org/licenses/by-nc/3.0) which permits unrestricted noncommercial use, distribution, and reproduction in any medium, provided the original work is properly cited. 


\section{INTRODUCTION}

Patient-centered care, in contrast to doctor-centered, refers to understanding a patient as a unique human-being, ${ }^{1)}$ trying to grasp the thoughts and feelings of the patient, to communicate kindly with the patient (a concept of 'caring'), ${ }^{2)}$ and establishing a relationship of sharing medical information and power-sharing between doctors and patients (a concept of 'sharing')."

As compared to the traditional doctor-patient relationship, patient-centered care is an evidence-based concept for improving clinical outcomes and patient satisfaction. ${ }^{4-6)}$ Due to its important benefits for patients, more emphasis has been placed on it in current practice. ${ }^{7-9)}$ However, its implementation in practice is limited because the traditional model of the doctor-patient relationship, such as the authoritative doctor and the passive, receptive patient, still dominates doctor-patient encounters. Indeed, although patients are a central component of the healthcare system, the patients' perspectives or preferences about patient-centered care have not been considered by healthcare providers. ${ }^{10)}$ Thus, understanding the patients' expectations regarding patient-centered care would be the first step in implementing patient-centeredness in clinical practice.

Changes in the healthcare environment deserve special attention due to the following reasons: (1) The availability of medical information and knowledge has been increasing due to the internet or other media. ${ }^{11)}$ Owing to this easier access to medical information and knowledge, patients are increasingly interested in healthcare issues than before. Moreover, they now have more access to alternative opinions about their diagnosis and treatment. ${ }^{12)}$ These changes may affect patients' perspectives about the doctor-patient relationship. (2) The number of patients who consider themselves as a medical consumer, who claim the right to appropriate medical services based on the recognition that they deserve special treatment, is increasing. ${ }^{13,14)}$ Moreover, there is a tendency that medical consumers are spending more of their own income on health care, with an estimated increase of $2.5 \%$ to $3.5 \%$ per year with increasing age. ${ }^{11)}$

As described above, the medical environment has been undergoing continual changes. It is therefore imperative that clinicians recognize the changing trends in the degree of patient expectations for patient-centered care based on the sharing and caring concept, which is essential for effectively implementing patient-centered care in a clinical setting. However, there is a paucity of clinical research about the change in the patients' attitudes toward patient-centered care in a primary care setting. Moreover, there is also a possibility that considering sociodemographic factors, specific approaches for a patient population might help to implement patient-centered care in a clinical setting. Thus, it would be meaningful to examine whether changes in the degree of patient expectations for patient-centered care, if any, are associated with specific demographic factors. Given the above background, we conducted this study to examine the changes in the degree of patient expectations for patientcentered care and the related socio-demographic factors in a primary care setting over a 5-year period.

\section{METHODS}

\section{Subjects and Research Design}

The current study was conducted in two phases (phase I: March-July, 2005 and phase II: March- 
July, 2010). In each phase, we performed a self-report questionnaire survey. In phase I, 400 patients from ten different family medicine clinics at Seoul or Gyeonggi province in South Korea were given questionnaires. We excluded the patients who were aged 20 years or younger, and those who were deemed to have an inability to complete a self-report questionnaire because of health problems such as visual or mental problems. We collected back 384 questionnaires from the patients who participated in the phase I study. Further, we excluded the patients who did not fully respond to the Patient-Practitioner Orientation Scale (PPOS) items from the current analysis. Thus, 359 patients participated in the phase I study. The phase II study was conducted in the same way as phase I. The clinics from which the participants were recruited and exclusion criteria were the same as those employed in phase I. We collected 492 out of the 500 questionnaires distributed to the patients who participated in the phase II study. Excluding the patients who did not fully respond to the PPOS items, we analyzed 468 questionnaires in phase II.

We obtained a written informed consent from all the patients. The current study was approved by the institutional review board of the Catholic University of Korea (IRB approval number: KC10EISI0056).

\section{Instruments}

In phases I and II, the patients were asked to complete a self-report questionnaire based on the PPOS. The PPOS, which was used to measure the degree of patients' expectations for patient-centered care in the current study, was first developed by Krupat et al. ${ }^{15,16}$ in an effort to measure the attitudes of either patients or clinicians towards aspects of the physician-patient relationship (e.g., patient- or doctor-centeredness). Translated into Korean by Sohn et al., ${ }^{17)}$ and used by several Korean studies, ${ }^{18-20)}$ the PPOS comprises 18 items on a 6-point Likert format. It includes two nine-item subscales measuring 'sharing' and 'caring' scores, respectively. These subscales are based on the degree of belief that patients should be well informed by doctors and this should be a decision-making process between the two parties, and that patients should be well taken care of, respectively. The mean PPOS score is the average value for all 18 items. The 'sharing' and 'caring' scores are calculated by averaging values for the nine items in the subscale. Values closer to 6 are indicative of a higher degree of patient-centered responses. Conversely, values closer to 1 are indicative of a higher degree of doctor-centered responses. The test-retest reliability of the tool was $r=0.75$ and the Cronbach's alpha for internal consistency was 0.63 . Patients were also asked to report their socio-demographic variables such as age, gender, marital status, education level, monthly income, chronic diseases, and functional health status.

\section{Statistical Analysis}

We used the chi-square test to compare phase I and II in terms of the demographic characteristics and changes in the degree of patient agreement on each item. We analyzed the differences in the mean PPOS scores and 'sharing' and 'caring' scores between phase I and II, using analysis of covariance for covariates such as gender, age, marital status, education level, monthly income, functional health status, and chronic diseases. We also used a two-way nested analysis of variance to analyze the differences in the mean PPOS scores and 'sharing' and 'caring' scores in terms of the demographic variables within year. The statistical analysis was done using the PASW ver. 18.0 (SPSS Inc., Chicago, IL, USA) for Windows. A P-value of $<0.05$ was considered statistically significant. 


\section{RESULTS}

\section{Socio-Demographic Characteristics of the Patients}

As shown in Table 1, there were differences in the age, marital status, education level, monthly income, and functional health status of the participants in phase I and II. However, there were no differences in gender, and a history of chronic diseases.

Table 1. Socio-demographic characteristics in each phase

\begin{tabular}{|c|c|c|c|}
\hline Characteristic & $2005(n=359)$ & $2010(n=468)$ & P-value \\
\hline Gender & & & 0.229 \\
\hline Men & $145(40.4)$ & $209(44.7)$ & \\
\hline Women & $214(59.6)$ & $259(55.3)$ & \\
\hline Age (y) & & & $<0.001$ \\
\hline $20-39$ & $248(69.1)$ & $277(59.1)$ & \\
\hline $40-59$ & $102(28.4)$ & $128(27.4)$ & \\
\hline$\geq 60$ & $9(2.5)$ & $63(13.5)$ & \\
\hline Marital status & & & $<0.001$ \\
\hline Never married & $122(34.0)$ & $161(34.4)$ & \\
\hline Currently married & $215(59.9)$ & $234(50.0)$ & \\
\hline Others ${ }^{*}$ & $22(6.1)$ & $73(15.6)$ & \\
\hline Education & & & 0.004 \\
\hline$\leq$ Middle school & $31(8.7)$ & $74(15.8)$ & \\
\hline High school & $134(37.3)$ & $143(30.6)$ & \\
\hline$\geq$ College & $194(54.0)$ & $251(53.6)$ & \\
\hline Monthly income (10,000 KRW) & & & 0.032 \\
\hline$<200$ & $120(33.4)$ & $144(30.7)$ & \\
\hline $200-399$ & $173(48.2)$ & $202(43.1)$ & \\
\hline$\geq 400$ & $66(18.4)$ & $122(26.2)$ & \\
\hline Functional health status & & & 0.009 \\
\hline Good & $223(62.1)$ & $336(71.8)$ & \\
\hline Fair & 118 (32.9) & 119 (25.4) & \\
\hline Poor & $18(5.0)$ & $13(2.8)$ & \\
\hline Chronic disease & & & 0.096 \\
\hline Present & $72(20.1)$ & $117(25.0)$ & \\
\hline Absent & $287(79.9)$ & $351(75.0)$ & \\
\hline
\end{tabular}

Values are presented as frequencies (\%).

*Separated/divorced/widowed. Student, housewife, unemployed.

\section{Changes in Mean PPOS Scores and 'Sharing' and 'Caring' Scores over a 5-Year Period} after Adjusting for Socio-Demographic Factors

As shown in Figure 1, in phase II, as compared with phase I, the mean PPOS scores were lower ( $3.84 \pm$ 0.51 vs. $3.75 \pm 0.41 ; \mathrm{P}=0.004)$, 'sharing' scores were higher $(3.67 \pm 0.68$ vs. $3.82 \pm 0.44 ; \mathrm{P}<0.001)$ and 'caring' scores were lower ( $4.01 \pm 0.57$ vs. $3.67 \pm 0.58 ; \mathrm{P}=0.001)$ after adjusting for gender, age, marital status, education level, monthly income, functional health status, and chronic diseases. 


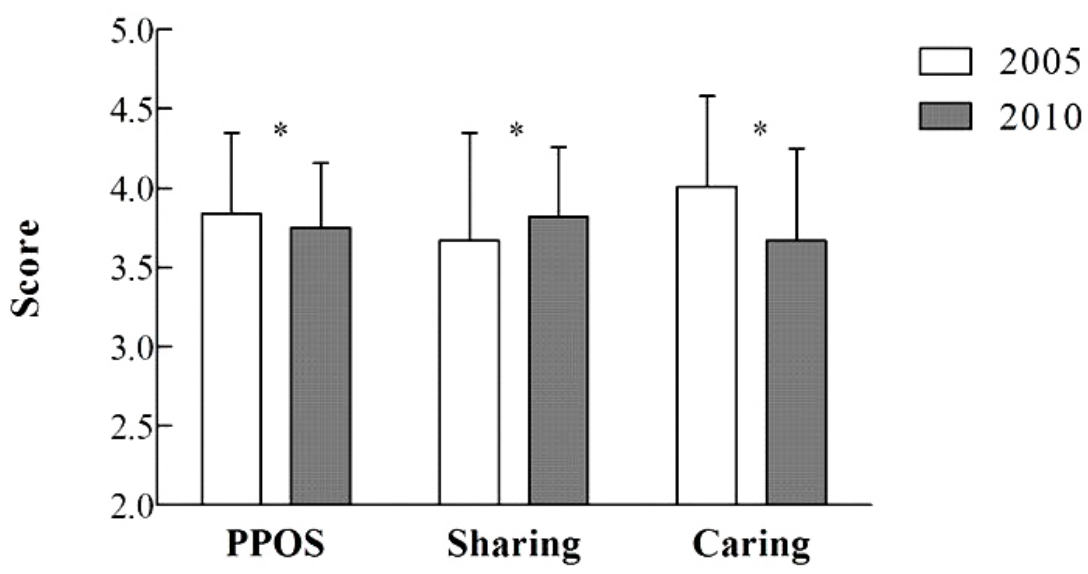

Figure 1. Changes in the mean PPOS score and 'sharing' and 'caring' scores over a 5-year period in primary care setting. ${ }^{*} \mathrm{P}<0.01$. Values are expressed after adjusting for covariates such as gender, age, marital status, education, income, functional health status, and presence of chronic diseases. PPOS: Patient-Practitioner Orientation Scale.

\section{The PPOS and Subscale Scores, and Their Changes Depending on Socio-Demographic Factors}

As shown in Table 2, there were no differences in the mean PPOS scores and 'sharing' and 'caring' scores between men and women in each phase. The mean PPOS scores and 'sharing' and 'caring' scores in each phase were higher in the younger patients with a higher income, higher educational level, and better functional health status. In phase II, there were differences in the mean PPOS scores and 'sharing' and 'caring' scores depending on the marital status. Specifically, they were lower in patients who were 'never married,' 'currently married,' and 'others' (separated, divorced, or widowed) in the corresponding order. In phase II, as compared with phase I, the 'sharing' scores were higher and 'caring' scores were lower in all most subgroups of patients, except for those aged 60 years or older, those who reported their marital status as 'separated,' 'divorced,' or 'widowed,' those who were educated up to 'lower than middle school level,' those with a 'low monthly income,' those with 'fair and poor function health status,' and those with chronic diseases.

\section{Differences in the Degree of Patient Agreement on PPOS Items between Phase I and II}

The degree of patient agreement on the items, "The doctor is the one who should decide what gets talked about during a visit" and "Although healthcare is less personal these days, this is a small price to pay for medical advances" was higher in phase II as compared with phase I ( $47.9 \%$ vs. $58.1 \%$; P = 0.004 , and $30.9 \%$ vs. $39.5 \% ; \mathrm{P}=0.010$, respectively). In contrast, as compared with that in phase I, in phase II, the degree of patient agreement was lower on the items, "When patients disagree with their doctor, this is a sign that the doctor does not have the patient's respect and trust" $(45.1 \%$ vs. $38.0 \%$; $\mathrm{P}=$ $0.040)$, "The patient must always be aware that the doctor is in charge" (54.3\% vs. $47.2 \% ; \mathrm{P}=0.043)$, " $\mathrm{A}$ treatment plan cannot succeed if it is in conflict with a patient's lifestyle or values" (59.9\% vs. $52.1 \%$; P = 
0.026), and "Humor is a major ingredient in the doctor's treatment of the patient" $(72.4 \%$ vs. $64.1 \%$; $\mathrm{P}=$ 0.011) (Table 3).

Table 2. Socio-demographic factors depending on the PPOS and subscale scores

\begin{tabular}{|c|c|c|c|c|c|c|c|c|c|}
\hline \multirow{2}{*}{ Variable } & \multicolumn{2}{|c|}{ PPOS score } & \multirow{2}{*}{ P-value* } & \multicolumn{2}{|c|}{ Sharing score } & \multirow{2}{*}{ P-value ${ }^{*}$} & \multicolumn{2}{|c|}{ Caring score } & \multirow{2}{*}{ P-value* } \\
\hline & 2005 & 2010 & & 2005 & 2010 & & 2005 & 2010 & \\
\hline \multicolumn{10}{|l|}{ Gender } \\
\hline Men & $3.81(0.49)$ & $3.72(0.40)$ & 0.062 & $3.62(0.63)$ & $3.79(0.40)$ & 0.005 & $4.01(0.57)$ & $3.65(0.57)$ & $<0.001$ \\
\hline Women & $3.86(0.53)$ & $3.77(0.41)$ & 0.033 & $3.70(0.71)$ & $3.85(0.47)$ & 0.006 & $4.01(0.58)$ & $3.69(0.59)$ & $<0.001$ \\
\hline P-value ${ }^{\dagger}$ & 0.365 & 0.276 & & 0.170 & 0.305 & & 0.909 & 0.459 & \\
\hline \multicolumn{10}{|l|}{ Age (y) } \\
\hline $20-39$ & $3.89(0.53)$ & $3.80(0.41)$ & 0.036 & $3.72(0.69)$ & $3.85(0.45)$ & 0.010 & $4.05(0.60)$ & $3.76(0.56)$ & $<0.001$ \\
\hline $40-59$ & $3.74(0.47)$ & $3.76(0.40)$ & 0.819 & $3.58(0.66)$ & $3.85(0.42)$ & $<0.001$ & $3.91(0.49)$ & $3.66(0.60)$ & 0.001 \\
\hline$\geq 60$ & $3.68(0.24)$ & $3.48(0.34)$ & 0.206 & $3.40(0.28)$ & $3.67(0.44)$ & 0.188 & $3.96(0.41)$ & $3.29(0.52)$ & 0.001 \\
\hline P-value ${ }^{\dagger}$ & 0.001 & $<0.001$ & & 0.034 & 0.056 & & 0.098 & $<0.001$ & \\
\hline \multicolumn{10}{|l|}{ Marital status } \\
\hline Never married & $3.88(0.55)$ & $3.85(0.40)$ & 0.513 & $3.67(0.67)$ & $3.91(0.42)$ & $<0.001$ & $4.10(0.59)$ & $3.78(0.56)$ & $<0.001$ \\
\hline Currently married & $3.82(0.50)$ & $3.75(0.41)$ & 0.081 & $3.68(0.68)$ & $3.83(0.44)$ & 0.003 & $3.97(0.55)$ & $3.66(0.60)$ & $<0.001$ \\
\hline Other $^{\ddagger}$ & $3.77(0.47)$ & $3.52(0.32)$ & 0.023 & $3.63(0.71)$ & $3.59(0.40)$ & 0.744 & $3.90(0.60)$ & $3.44(0.51)$ & 0.001 \\
\hline P-value ${ }^{\dagger}$ & 0.376 & $<0.001$ & & 0.940 & $<0.001$ & & 0.112 & $<0.001$ & \\
\hline \multicolumn{10}{|l|}{ Education } \\
\hline$\leq$ Middle school & $3.62(0.48)$ & $3.57(0.34)$ & 0.574 & $3.59(0.65)$ & $3.69(0.39)$ & 0.383 & $3.65(0.39)$ & $3.44(0.56)$ & 0.079 \\
\hline High school & $3.80(0.52)$ & $3.78(0.37)$ & 0.693 & $3.66(0.72)$ & $3.80(0.42)$ & 0.044 & $3.93(0.60)$ & $3.77(0.54)$ & 0.017 \\
\hline$\geq$ College & $3.90(0.50)$ & $3.78(0.44)$ & 0.004 & $3.69(0.65)$ & $3.87(0.46)$ & 0.001 & $4.12(0.54)$ & $3.68(0.60)$ & $<0.001$ \\
\hline P-value ${ }^{\dagger}$ & 0.002 & 0.001 & & 0.635 & 0.045 & & $<0.001$ & $<0.001$ & \\
\hline \multicolumn{10}{|l|}{$\begin{array}{r}\text { Monthly income } \\
(10,000 \mathrm{KRW})\end{array}$} \\
\hline$<200$ & $3.82(0.56)$ & $3.67(0.41)$ & 0.005 & $3.70(0.77)$ & $3.75(0.43)$ & 0.505 & $3.94(0.61)$ & $3.58(0.62)$ & $<0.001$ \\
\hline $200-399$ & $3.79(0.49)$ & $3.72(0.37)$ & 0.145 & $3.61(0.62)$ & $3.78(0.42)$ & 0.003 & $3.98(0.54)$ & $3.67(0.53)$ & $<0.001$ \\
\hline$\geq 400$ & $3.99(0.47)$ & $3.88(0.45)$ & 0.095 & $3.79(0.64)$ & $3.99(0.45)$ & 0.021 & $4.20(0.53)$ & $3.77(0.61)$ & $<0.001$ \\
\hline P-value ${ }^{\dagger}$ & 0.009 & 0.001 & & 0.056 & 0.001 & & 0.012 & 0.035 & \\
\hline \multicolumn{10}{|l|}{ Functional health status } \\
\hline Good & $3.88(0.52)$ & $3.82(0.41)$ & 0.097 & $3.73(0.70)$ & $3.89(0.44)$ & 0.001 & $4.04(0.55)$ & $3.74(0.59)$ & $<0.001$ \\
\hline Fair & $3.80(0.49)$ & $3.56(0.36)$ & $<0.001$ & $3.62(0.63)$ & $3.65(0.39)$ & 0.732 & $3.97(0.59)$ & $3.48(0.54)$ & $<0.001$ \\
\hline Poor & $3.60(0.51)$ & $3.57(0.30)$ & 0.859 & $3.31(0.58)$ & $3.64(0.39)$ & 0.106 & $3.88(0.66)$ & $3.50(0.42)$ & 0.067 \\
\hline P-value ${ }^{\dagger}$ & 0.017 & $<0.001$ & & $<0.001$ & $<0.001$ & & 0.383 & $<0.001$ & \\
\hline \multicolumn{10}{|l|}{ Chronic disease } \\
\hline Present & $3.84(0.49)$ & $3.67(0.43)$ & 0.016 & $3.75(0.66)$ & $3.77(0.46)$ & 0.776 & $3.93(0.56)$ & $3.57(0.57)$ & $<0.001$ \\
\hline Absent & $3.84(0.52)$ & $3.77(0.40)$ & 0.058 & $3.65(0.68)$ & $3.84(0.43)$ & $<0.001$ & $4.03(0.57)$ & $3.70(0.59)$ & $<0.001$ \\
\hline P-value ${ }^{\dagger}$ & 0.969 & 0.044 & & 0.213 & 0.233 & & 0.206 & 0.041 & \\
\hline
\end{tabular}

Values are presented as means (SD).

PPOS: Patient-Practitioner Orientation Scale.

${ }^{*} \mathrm{P}$-value for difference in scores in each phase within each socio-demographic factor. ${ }^{\dagger} \mathrm{P}$-value for difference of scores according to socio-demographic factor within each year. ${ }^{\star}$ Separated, divorced, widowed. Student, housewife, unemployed. 
Table 3. The degree of patient agreement on each item in each phase

\begin{tabular}{|c|c|c|c|}
\hline \multirow{2}{*}{ Patient-Practitioner Orientation Scale items ${ }^{*}$} & \multicolumn{2}{|c|}{ Agreement \% } & \multirow{2}{*}{ P-value } \\
\hline & 2005 & 2010 & \\
\hline \multicolumn{4}{|l|}{ Sharing items } \\
\hline The doctor is the one who should decide what gets talked about during a visit. & 47.9 & 58.1 & 0.004 \\
\hline It is often best for patients if they do not have a full explanation of their medical condition. & 38.7 & 37.2 & 0.651 \\
\hline Patients should rely on their doctors' knowledge and not try to find out their conditions on their own. & 62.4 & 60.0 & 0.492 \\
\hline Many patients continue asking questions even though they are not learning anything new. & 59.6 & 59.0 & 0.854 \\
\hline Patients should be treated as if they were partners with the doctor, equal in power and status. & 34.8 & 37.0 & 0.524 \\
\hline Patients generally want reassurance rather than information about their health. & 50.4 & 54.5 & 0.245 \\
\hline When patients disagree with their doctor, this is a sign that the doctor does not have the patient's respect and trust. & 45.1 & 38.0 & 0.040 \\
\hline The patient must always be aware that the doctor is in charge. & 54.3 & 47.2 & 0.043 \\
\hline When patients look up medical information on their own, this usually confuses more than it helps. & 34.0 & 32.1 & 0.558 \\
\hline \multicolumn{4}{|l|}{ Caring items } \\
\hline Although health care is less personal these days, this is a small price to pay for medical advances. & 30.9 & 39.5 & 0.010 \\
\hline The most important part of the standard medical visit is the physical exam. & 54.6 & 58.8 & 0.231 \\
\hline When doctors ask a lot of questions about a patient's background, they are prying too much into personal matters. & 50.1 & 55.1 & 0.154 \\
\hline If doctors are truly good at diagnosis and treatment, the way they relate to patients is not that important. & 22.6 & 23.7 & 0.697 \\
\hline If a doctor's primary tools are being open and warm, the doctor will not have a lot of success. & 25.6 & 28.6 & 0.336 \\
\hline A treatment plan cannot succeed if it is in conflict with a patient's lifestyle or values. & 59.9 & 52.1 & 0.026 \\
\hline Most patients want to get in and out of the doctor's office as quickly as possible & 45.1 & 42.1 & 0.383 \\
\hline It is not that important to know a patient's culture and background in order to treat the person's illness & 26.2 & 26.9 & 0.812 \\
\hline Humor is a major ingredient in the doctor's treatment of the patient. & 72.4 & 64.1 & 0.011 \\
\hline
\end{tabular}

The percentage agreement (\%) is defined as the proportion of patients who responded as 'rather agree,' 'agree,' or 'strongly agree.'

*Responses to Likert-scaled questions.

\section{DISCUSSION}

Identifying the patients' expectations from clinical consultations could be a key factor in improving the degree of patient satisfaction with clinical outcomes and establishing a favorable relationship between clinicians and patients, especially in a continually changing medical environment. We therefore examined the change in the degree of patient expectations for patient-centered care over a 5 -year period, as well as the related socio-demographic factors.

In the current study, we found that 'sharing' scores were higher in 2010 as compared to those in 2005. The degree of patient expectations for sharing medical information and the power in the decision-making process, i.e., the sharing concept, was subject to various factors such as age, education level, and other demographic characteristics, as well as their underlying medical conditions. ${ }^{21-23)}$ However, it was interesting to note that there was a significant change in the degree of expectations even adjusting for the impact of socio-demographic factors. It is also noteworthy that the degree of patient agreement on items "When patients disagree with their doctor, this is a sign that the doctor does not have the patient's respect and trust" and "The patient must always be aware that the doctor is in charge" was lower in 2010 as compared with that in 2005. These results indicate that the degree of patients' expectations on the sharing concept increased over the 5-year period. Patients' expectations 
or preferences about the sharing concept has been of increasing concern due to the increased exposure to medical information through various means, ${ }^{11,12)}$ the increased recognition that patients constitute an essential component of the healthcare system, ${ }^{10)}$ and a consensus that they have a right to be fully informed about and share the decision-making process with clinicians. ${ }^{13,14)}$ In addition, previous literature indicates that physical and psychological outcomes would be improved when medical information and the decision-making process is shared between the two parties involved. ${ }^{3,5,24)}$

Our results showed that the 'caring' score was higher than the 'sharing' one in the participants of phase I (in 2005), which was not in agreement with previous literature. ${ }^{15,23)}$ In phase II (in 2010), however, the 'caring' score was lower than the 'sharing' one. This suggests that the degree of patients' concern about the clinicians' interest in patient's feelings and psychosocial perspectives was lower in 2010 than in 2005. Specifically, in 2010, as compared with 2005, the degree of patient agreement on the item "If healthcare is less personal these days, this is a small price to pay for the medical advances" was higher and that on items such as "A treatment plan cannot succeed if it is in conflict with a patient's lifestyle or values" and "A friendly manner is a major ingredient in the doctor's treatment of the patient." The probable cause for the decrease in the 'caring' score over a 5-year period could be that Korean patients think of the affectionate relationship between physicians and patients as an unrealistic thing, owing to the formal environment in the Korean medical setting (e.g., limited time for consultation).

Our results showed that the mean PPOS and subscale scores were higher in the younger patients with a higher level of education, a higher monthly income, and a higher health functional status, which is consistent with the findings of previous reports, ${ }^{25)}$ but there was no sex-related difference in the scores. It is also noteworthy that there were similar trends in the changes in 'sharing' and 'caring' scores (higher 'sharing' score and lower 'caring' score over a 5-year period) in a subgroup of patients, which was assigned based on socio-demographic factors, except for a few other subgroups. As a single, standardized approach without considering the patients' expectations with reference to the related socio-demographic factors would not be consistently effective for all the patients, these results are of significance in that they might be applicable only to a specific subgroup of patients in a clinical setting.

Thus, there are some limitations to the current study. (1) We enrolled only the patients who visited the outpatient clinic of the department of family medicine in some areas. It is therefore unavoidable that a selection bias was involved in the current study. (2) We did not consider the disease-related factors, such as the severity of diseases, but evaluated the presence of chronic diseases only.

Despite these limitations, our results are of significance in that this is the first attempt to evaluate changes in the degree of expectations of patients about patient-centered care in a primary care setting. Moreover, because patient-centered care plays a pivotal role in disease prevention and health promotion, ${ }^{26-28)}$ these findings could be a significant cornerstone in implementing patient-centered approaches in a primary healthcare setting.

To summarize, our results were as follows: (1) The 'sharing' score of patients in a primary care setting increased and 'caring' one decreased over a 5-year period. (2) The mean PPOS and subscale 
scores in each phase of the study were associated with some socio-demographic factors of patients, such as age, monthly income, education level, marital status, and functional health status.

In conclusion, our results suggest that clinicians need to be more flexible to adapt themselves to the patients' preferences and provide patient-centered care for patients in a primary care setting. This is possible if clinicians are aware of the degree of patients' expectations for it, which might eventually lead to the improvement of clinical outcomes as well as the relationship between the two parties.

\section{CONFLICT OF INTEREST}

No potential conflict of interest relevant to this article was reported.

\section{REFERENCES}

1. Balint E. The possibilities of patient-centered medicine. J R Coll Gen Pract 1969;17:269-76.

2. Henbest RJ, Stewart MA. Patient-centredness in the consultation. 1: A method for measurement. Fam Pract 1989;6:249-53.

3. Institute of Medicine. Crossing the quality chasm: a new health system for the 21 st century. Washington (DC): National Academy Press; 2001.

4. Glickman SW, Boulding W, Manary M, Staelin R, Roe MT, Wolosin RJ, et al. Patient satisfaction and its relationship with clinical quality and inpatient mortality in acute myocardial infarction. Circ Cardiovasc Qual Outcomes 2010;3:188-95.

5. Kaplan SH, Greenfield S, Ware JE Jr. Assessing the effects of physician-patient interactions on the outcomes of chronic disease. Med Care 1989;27(3 Suppl):S110-27.

6. Meterko M, Wright S, Lin H, Lowy E, Cleary PD. Mortality among patients with acute myocardial infarction: the influences of patient-centered care and evidence-based medicine. Health Serv Res 2010;45(5 Pt 1):1188-204.

7. Yellowlees P, Nafiz N. The psychiatrist-patient relationship of the future: anytime, anywhere? Harv Rev Psychiatry 2010;18:96-102.

8. Siebzehner MI, Balik C, Matalon A. Doctor-patient relationship in the context of a changing society. Harefuah 2008;147:1010-5, 1027, 1026.

9. Alden DL, Merz MY, Akashi J. Young adult preferences for physician decision-making style in Japan and the United States. Asia Pac J Public Health 2012;24:173-84.

10. Rozenblum R, Lisby M, Hockey PM, Levtzion-Korach O, Salzberg CA, Efrati N, et al. The patient satisfaction chasm: the gap between hospital management and frontline clinicians. BMJ Qual Saf 2013;22:242-50.

11. Yellowlees P. Your health in the information age: how you and your doctor can use the Internet to work together. New York: iUniverse; 2008.

12. Grain H. Consumer issues in informatics. In: Conrick M, editor. Health informatics: transforming healthcare 
with technology. Melbourne: Thomson Social Science Press; 2006. p. 333-44.

13. Jha AK, Orav EJ, Zheng J, Epstein AM. Patients' perception of hospital care in the United States. N Engl J Med 2008;359:1921-31.

14. Stewart M, Brown JB, Weston WW, McWhinney IR, McWilliam C, Freeman TR. The fifth component: enhancing the patient-doctor relationship. In: Stewart M, Brown JB, editors. Patient-centered medicine: transforming the clinical method. Abingdon: Radcliffe Medical Press; 2003. p. 117-30.

15. KrupatE, Rosenkranz SL, Yeager CM, Barnard K, Putnam SM, Inui TS. The practice orientations of physicians and patients: the effect of doctor-patient congruence on satisfaction. Patient Educ Couns 2000;39:49-59.

16. Krupat E, Yeager CM, Putnam S. Patient role orientations, doctor-patient fit, and visit satisfaction. Psychol Health 2000;15:707-19.

17. Sohn IK, Lee JH, Cho IH, Nam BW, Park KU, Lee KH, et al. Patient-centeredness in faculties, residents and medical students. J Korean Neuropsychiatr Assoc 2002;41:290-7.

18. Choi CJ, Kim JM, Park YG. Patient-centered attitudes and communication skills in medical students after clerkship. Korean J Med Educ 2004;16:169-77.

19. Moon SW, Nam BW, Seo JS, Ryu EJ, Kweon HJ, Sohn IK, et al. Patient-centeredness associated with personality traits of medical students. Korean J Med Educ 2006;18:77-86.

20. Hwang SW, Choi CJ. Patient-centered attitudes in primary care patients. J Korean Acad Fam Med 2006;27:998-1004.

21. Ford S, Schofield T, Hope T. Are patients' decision-making preferences being met? Health Expect 2003;6:72-80.

22. Dowsett SM, Saul JL, Butow PN, Dunn SM, Boyer MJ, Findlow R, et al. Communication styles in the cancer consultation: preferences for a patient-centred approach. Psychooncology 2000;9:147-56.

23. Ogden J, Ambrose L, Khadra A, Manthri S, Symons L, Vass A, et al. A questionnaire study of GPs' and patients' beliefs about the different components of patient centredness. Patient Educ Couns 2002;47:223-7.

24. Main CJ, Buchbinder R, Porcheret M, Foster N. Addressing patient beliefs and expectations in the consultation. Best Pract Res Clin Rheumatol 2010;24:219-25.

25. Krupat E, Bell RA, Kravitz RL, Thom D, Azari R. When physicians and patients think alike: patient-centered beliefs and their impact on satisfaction and trust. J Fam Pract 2001;50:1057-62.

26. Ash S, Reeves M, Bauer J, Dover T, Vivanti A, Leong C, et al. A randomised control trial comparing lifestyle groups, individual counselling and written information in the management of weight and health outcomes over 12 months. Int J Obes (Lond) 2006;30:1557-64.

27. Chi CL, Nick Street W, Robinson JG, Crawford MA. Individualized patient-centered lifestyle recommendations: an expert system for communicating patient specific cardiovascular risk information and prioritizing lifestyle options. J Biomed Inform 2012;45:1164-74.

28. Little P, Everitt H, Williamson I, Warner G, Moore M, Gould C, et al. Preferences of patients for patient centred approach to consultation in primary care: observational study. BMJ 2001;322:468-72. 